\title{
Synthesis of Eburnane-Type Alkaloids
}

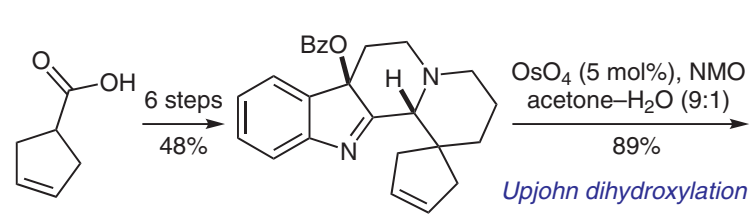

A<smiles>CC12N3CCCC45CC(C4)N1c1ccccc1C(O)C2(CC3)C5</smiles>

B

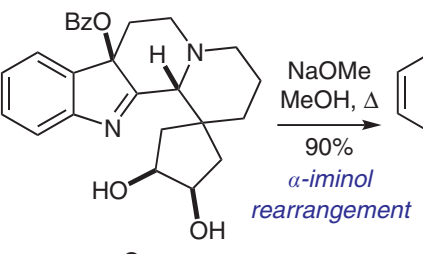

C
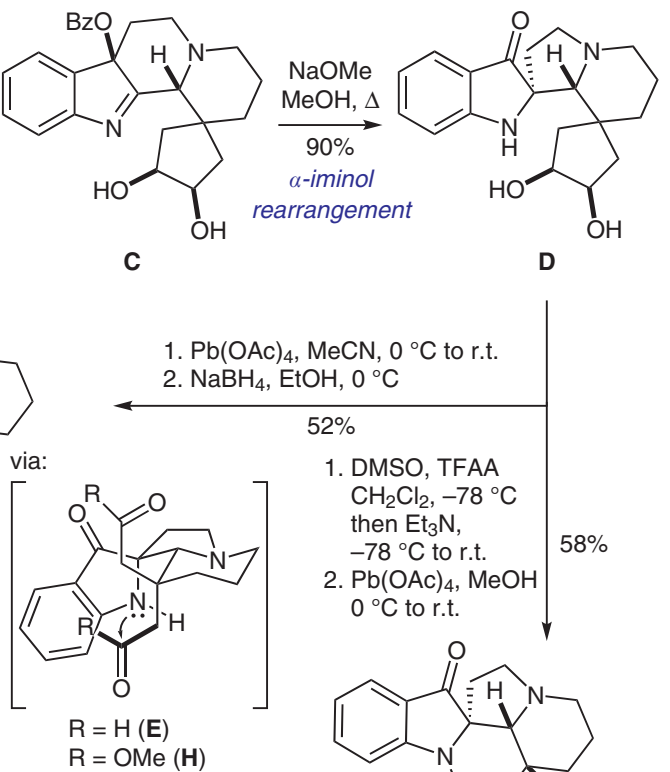

Category

Synthesis of Natural

Products and

Potential Drugs

\section{Key words}

( \pm )-eburnamonine

( \pm )-larutensine

( \pm )-melokhanine $E$

(士)-terengganensine $B$

Upjohn

dihydroxylation

$\alpha$-iminol

rearrangement

aza-Pinacol

rearrangement
Significance: Zhu and co-workers present their recent efforts to access eburnane-type alkaloids using a highly divergent approach. The presented route features an $\alpha$-iminol rearrangement to access the trans-fused core in intermediate $\mathbf{D}$. The conformational bias allowed to close the remaining sixmembered ring of the eburnane core in a diastereoselective fashion. The divergent design of the route uses key intermediates $\mathbf{D}$ and $\mathbf{E}$ to access four different eburnane alkaloids with good yields.
Comment: $\alpha$-Iminol rearrangement of Cled to key intermediate $\mathbf{D}$. Oxidative cleavage of the diol and reduction yielded hexacyclic aminal $\mathbf{F}$ as a single diastereomer. Lewis acid induced 1,2-alkyl shift of $\mathbf{F}$ furnished $( \pm$ )-terengganensine B. Reduction to alcohol $\mathrm{G}$ and Brønsted acid mediated rearrangement allowed synthesis of $( \pm$ )-larutensine. Oxidation of diol $\mathbf{D}$ to the corresponding diketone and subsequent oxidative bond cleavage gave pentacyclic amide $\mathbf{I}$. $( \pm)$-Melokhanine $E$ was obtained in five additional steps and was then converted into ( \pm )-eburnamonine by means of an aza-pinacol rearrangement. 